УдК 930.272

\title{
С.С. Бытко
}

\section{ПОЛЕМИЧЕСКАЯ КУЛЬТУРА СТАРОВЕРОВ И СТРУКТУРА РУКОПИСНОГО СБОРНИКА КОНЦА ХІХ в.: ОСОБЕННОСТИ ВЗАИМОДЕЙСТВИЯ}

\begin{abstract}
Представлены результаты изучения старообрядческого рукописного полемического сборника конца ХІХ в. Рассматриваются особенности структурного устройства сборника, а также предпринимается попытка его атрибуции. Установлено, что книга была написана в среде консервативно-настроенных сибирских поморцев. Выделены особенности взаимодействия отдельных произведений внутри компиляции, для усиления полемического эффекта построенные на взаимодополнении, а также чередовании «рационалистических» и «эмфатических» произведений.

Ключевые слова: старообрядческие компиляции; кириллическая традиция; полемический сборник; староверие; книжность; рукопись.
\end{abstract}

На сегодняшний день старообрядчество является одной из наиболее перспективных тем для изучения в сфере истории, филологии и множестве смежных научных дисциплин. Современных исследователей занимает весьма интенсивная деятельность старообрядческих лидеров, внесших определяющий вклад в сохранение и развитие кириллической книжности XVII-XX вв. Вместе с тем результаты их трудов, приумноживших богатство славяно-русской книжной традиции, во многом остаются неизученными. Многочисленные работы московских, новосибирских и екатеринбургских исследователей продолжают обозначать новые проблемы, требующие решения.

Среди этих проблем остается «устройство» старопечатных и рукописных компиляций, бытовавших в среде староверов. Так, в фондах Томского областного краеведческого музея хранится занимательная рукопись [1], содержащая как множество излюбленных старообрядцами сюжетов, так и произведения, не пользовавшиеся столь же заметной популярностью. Сборник выполнен аккуратным поздним полууставом и насчитывает 250 л. В.А. Есипова датирует его концом XIX в. В настоящей статье предпринимается попытка анализа данного труда, ее атрибуции и выяснения принципов комплектования вошедших в нее текстов.

Книга насчитывает 52 сочинения преимущественно дореформенного происхождения. Сборник открывается достаточно распространенным в рукописной старообрядческой традиции «Разговором между книжником и мальчиком» [1. Л. 1-4 об.]. Следует заметить, что данное сочинение задает общий «повествовательный тон» всей компиляции, в силу чего, по всей видимости, и было расположено в начале сборника. Н.А. Старухин отмечал, что зачастую произведения, имевшие концептуальное значение, по замыслу составителей должны были открывать компиляцию [4. С. 114]. Специфический полемико-нравоучительный текст «Разговора...» как нельзя лучше передает общую направленность последующих частей книги.

Интересно, что произведение было создано в конце XVIII в. в «демократических» кругах уральского населения, не принадлежавшего, однако, к среде староверов. Первоначально критиковавшее главным образом идеологию просвещенного абсолютизма, оно было со временем взято на вооружение староверами для ведения полемики уже с миссионерами официальной церкви [6. С. 236].

Произведение выполнено в популярной для «низовой» литературы вопросно-ответной форме и представляет собой «состязание» мальчика с «грамотеем», который «...все книги <..> прочитал и знает их наизусть...» [1. Л. 1]. Форма подобного повествования позволяла староверам весьма эффективно использовать его полемический «потенциал». С одной стороны, автор получал возможность в увлекательной для читателя форме изобразить абсолютное доминирование в споре симпатичного, согласно его убеждениям, персонажа [5. С. 121]. Вместе с тем Р.Г. Пихоя выделяет несколько редакций «Разговора...», каждую из которых книжники легко адаптировали к потребностям собственной аудитории путем добавления и изъятия из текста отдельных полемических вопросов [6. С. 229].

В состязании мальчик, олицетворяющий собой простоту истины, не обремененную ношей черствого рационализма, наносит уверенное поражение воплощению косности и неумелого умствования. По мнению Р.Г. Пихои, особый контраст, возникавший при противопоставлении юного мальчика и ученого мужа, должен был еще более подчеркнуть тяжесть посрамления, нанесенного философу [Там же. С. 230]. Позже множество сходных произведений конца XVIII в., направленных против ученых философствований, были взяты на вооружение старообрядцами и получили распространение в составе сборников [7. С. 98]. Примечательно, что именно в примитивном заучивании риторических приемов и догматизме самих старообрядцев позже упрекали представители просвещенной части общества конца XIX в. [8. С. 77].

Возвращаясь к структуре сборника, следует заметить, что в составе компиляции сочинение утрачивает свои первоначальные нравоучительные мотивы, утверждавшие непостижимость знания о Боге. Вместо этого, используя последующие тексты, составитель концентрирует внимание читателя исключительно на полемических мотивах произведения. Основной его задачей при этом является показать пример решительного и убедительного «стояния за древлее благочестие».

Во второй части сборника представлено малоизвестное «Увещание христианина Мартына» [1. Л. 4 об. - 14], события которого относятся автором к 17 августа 1825 г. В тексте некий Мартын «из града 
Димитриева Московской губернии» держит ответ перед духовном собранием, члены которого, как выясняется, предъявляют тому обвинения в ереси. Произведение продолжает полемическую тематику, обозначенную в сборнике вступительным фрагментом. Одновременно с этим вторая глава значительно контрастирует с первой по форме повествования. Так, если «Разговор между книжником и мальчиком» не мог претендовать на какую-либо жизненность, «Увещание...» пытается представить описываемую беседу с тем реализмом, на какой могли быть способны старообрядческие книжники.

С первых строк сочинения автор обозначает главные условия успешной полемики с инославными выдержку, невозмутимость и достоинство. Представ перед собранием, Мартын начинает свое «стояние за веру» с поклона присутствующим [1. Л. 4 об.]. Уже этот фрагмент дает нам основание говорить о явной корреляции «Увещания...» с другим полемическим сочинением, приобретшим в среде староверов почти культовое значение, - «Прением дьякона Федора с митрополитом Афанасием». Та же манера держаться перед церковными властями, прославляемая книжником XVII в., повторяется и в сочинении XIX столетия [10. Л. 195 об.]. Помимо правил поведения на «судилище», одинаковыми оказываются также догматические рассуждения Федора и Мартына, даже сама структура диалогов.

В «Увещании...» герой объясняет причины непосещения им церкви, при этом характеризуя ее в следующих выражениях: «...мачеха $<$...> она о мне не радит и на спасенный путь не наставляет» [1. Л. 6 об.]. Далее следует ряд фрагментов, повторяющих «Прение...»: 1) полемика о перстосложении; 2) полемика об исправлении книг; 3) апелляция к авторитету святых; 4) призыв покориться под угрозой расправы; 5) нравственная дискредитация оппонентов (в «Прении...» митрополит Афанасий в пылу спора бьет себя кулаком по бедру, произнося: «Оу пропаль Хр[ис]тос, - ньсть єгш» [10. Л. 201-201 об.]; в «Увещании...» протопопы пытаются угостить Мартына табаком [1. Л. 11]); 6. поражение «никониан» и арест праведника. Подобное сходство можно объяснить, вспомнив вывод И.М. Грицевской о том, что все старообрядческое богословие берет свое начало из «Пятой соловецкой челобитной» [9. С. 289], которой, по всей видимости, и вдохновлялись авторы обоих произведений.

На угрозы «забрить (Мартына. - С.Б.) в солдаты» и содрать с него кожу «страдалец» отвечает собранию протопопов: «Вот вы и стали мучители, а не учители» [1. Л. 11]. В данной фразе содержится отсылка к широкому пласту старообрядческой книжности и поэтики. Как литературное явление обличение ложных учителей проникает в староверие из древнерусской традиции, где, в свою очередь, получает широкое распространение благодаря влиянию византийского «Слова о лжепророках и лжеучителях», изобилующего фразеологизмами о волках в овечьих шкурах применительно к духовенству [13. С. 174].

Насколько можно судить, впервые устойчивое сопоставление в рамках единой фразеологической конструкции «учителей» и «мучителей» появляется неза- долго до раскола. В 1636 г. группа нижегородских священников отправляет челобитную на имя патриарха Иосифа, обличающую безнравственное поведение современного им духовенства [14. С. 67-73]. Здесь же мы встречаем следующую фразу: «...именем пастыри, а делом волцы, только наречением и образом учителя, а произволением тяжцы мучители...». С развитием старообрядческой литературы «ревнители старых правил» перенимают обличительную риторику древнерусских писателей, после чего фразеологизм входит в широкое употребление. Так, распространение данного фразеологизма в среде «старолюбцев» было зафиксировано даже в 55-й лекции по русской истории В.О. Ключевского [12. С. 467].

За счет совпадения окончаний конструкция стала излюбленной для старообрядческого стихосложения. Н.В. Иванова указывает, что главной целью противопоставлений «иконы - картины», «крещение - обливание», «ладан - табак» и других становилось утверждение истинности старообрядческих церковных канонов [11. С. 28-29]. Так, первая часть оппозиции символизировала незыблемость веры, в то время как вторая выражала недопустимые новизны, наводнившие нынешний век. Священнники при этом воспринимались как носители враждебного учения и пафосно сравнивались с хулителями Христа [1. Л. 11 об.].

Подобно «Прению...» произведение оканчивается поражением сторонников «новизны» и арестом главного героя. В духе всех полемических сочинений дьякона Федора, призывающих сохранять веру и стойкость духа перед угрозой мучений, «Увещание...» отмечает, что Мартын, две недели просидевший в заточении и получавший в день лишь полфунта хлеба и «чашу малую воды», с радостью претерпел все мучения [Там же. С. 14]. Это в очередной раз дает нам право говорить о широком заимствовании элементов повествования у дьякона Иванова. Особого внимания заслуживает ремарка, отмечающая результаты диспута: «...победи от священных своим простодушием...». Данная фраза отсылает к первой главе сборника, отстаивавшей идеи «чистой, незамутненного истины». Таким образом, становятся ясны мотивы размещения двух сюжетов в непосредственной близости друг к другу. Первый текст задавал общую полемическую тональность книги, в то время как второй был призван представить реалистичный пример достойного «свидетеля истины».

Следующие четыре десятка текстов [1. Л. 14 об. 93] выполняют роль конвоя по отношению к первым двум сочинениям. На второстепенный для структуры сборника характер данных произведений указывает в первую очередь их объем, не превышающий 2-3 листов. Большинство текстов представлено сочинениями общехристианского происхождения. Незначительная часть (менее 15\%) относится к библейскому циклу или имеет апокрифический характер. Небольшое количество, а порой и полное отсутствие в подобных компиляциях непосредственно старообрядческих произведений не раз отмечалось исследователями старообрядческой книжной культуры [2. С. 202; 3. С. 59].

Включение в книгу широкого круга текстов дореформенного происхождения следует объяснять тра- 
дицией составления старообрядческих компиляций, для которой авторитетность сочинений напрямую связывалась с их архаичностью. В этом контексте весьма любопытным оказывается размещение «во главе» конвоя сравнительно поздних текстов, один из которых и вовсе имел нестарообрядческое происхождение. По всей видимости, это было сделано ввиду актуального для XIX в. полемического содержания, которым обладали «Разговор между книжником и мальчиком» и «Увещание христианина Мартына». Более ранние сочинения не могли с такой же злободневной точностью передать все аспекты противостояния старой веры и «недопустимой новизны», однако были необходимы как непременный атрибут древнерусской книжности.

Рассматривая содержание данного «блока» текстов в системе, можно обнаружить некоторые любопытные особенности. Несмотря на кажущуюся беспорядочность сочинений, они, тем не менее, объединены основной проблематикой: 1) правила проповеди; 2) эсхатологические рассуждения; 3) агиография мучеников; 4) осквернение от иноверцев. Сочинения различной тематики постоянно чередуются внутри «блока», при этом каждая из микротем многократно повторяется.

Проповедническая культура раскрывается в сборнике в двух своих ипостасях - воспитание и обращение. Регламентация догматической полемики, продолжающая основной мотив первых двух глав, ставит целью приобщение к идеалам «мира старообрядчества» лиц из числа инославных. При этом «Слово о наказании чад» [1. Л. 31 об. - 33] утверждает необходимость наставления в вере и «детей духовных». Принуждение к соблюдению церковных уставов воспринимается как одна из форм проповеди и спасения ближнего. Неотъемлемой чертой каждого проповедника Божьей истины объявляется высоконравственный образ жизни, рассуждения о котором также занимают значительное место в компиляции. Исследования старообрядчества показывают, что представители «древлего благочестия» воспринимались рядовым населением Урала и Сибири как поборники крайне целомудренного образа жизни [15. С. 127]. Поддержание данного образа, в свою очередь, обеспечивало прирост старообрядческих общин и являлось одним из факторов выживания их культурного наследия.

Эсхатологические мотивы структурно прикрепляются к нравоучительным и проповедническим сюжетам сборника. Наступление царства Антихриста напрямую соотносится с произошедшими в русской церкви обрядовыми изменениями. Ввиду этого традиционные для общехристианского наследия апокалиптические произведения в старообрядческом прочтении приобретают яркую антигосударственную окраску. В пятой главе читаем следующие слова: «...аще закон имать не прав, то не слушайте его» [1. Л. 21].

Эсхатологические сюжеты многократно указывают на истребление священнического и монашеского чина [1. Л. 17 об., 87 об. - 88], что обнаруживает беспоповское происхождение компиляции. Наряду с этим антигосударственные мотивы сборника характе- ризуют составителя как приверженца одного из радикальных согласий. Принимая во внимание время появления книги (конец XIX в.) и происходившее в тот период «смягчение» идеологии старолюбцев, перечень возможных толков сокращается до полудюжины.

Многочисленные агиографические сочинения, представленные в сборнике, почти без исключения представлены житиями мучеников. В компиляции они исполняют функции, сходные с «Увещанием христианина Мартына», а именно дополняют полемические мотивы книги живыми и эмоциональными примерами стояния за веру предков. Основными элементами повествования в житийных текстах сборника является страдание за истину Христову. Составитель книги формирует в уме читателя осознание того, что человек в мире победившего антихриста вынужден делать выбор между убиением тела и «огненной смертью» души. Последняя представляется более ужасной ввиду вечности посмертного бытия.

В качестве доказательства Божьего благоволения к мученикам составитель часто вводит в структуру компиляции жития, описывающие прижизненные и, что наиболее важно, посмертные примеры чудотворства страдальцев [1. Л. 30 об. - 31 об., 37-40, 40-43]. Более того, в 33-й главе мы читаем: «Хвала проповедникам и мученикам во спасение пришедшим» [Там же. Л. 73]. Данный фрагмент содержит явные указания на невозможность проповеди Божественных истин в отрыве от страдания. В доказательство неизбежности смерти грешников и справедливого наказания (данный мотив также широко распространен в старообрядческой книжности) составитель помещает в сборник апокриф «Слово о прении Петрове с Симоном волхвом» [Там же. Л. 79 об. - 82]. Так, прение апостола с нечестивцем оканчивается смертью последнего.

По мнению Н.В. Понырко и Е.М. Юхименко, стремительному распространению староверия на территории севера России способствовало его «героическое стояние за древнее благочестие» [16. С. 4]. Ввиду того побудительного воздействия, которое оказывала на читателя агиография в «связке» с догматически разработанными текстами, следует полагать, что составитель в конечном счете рассчитывал на бурный рост численности собственной общины и согласия. Кроме того, чередование «рационалистических» и эмфатических произведений в рамках единой компиляции не является редкостью и наблюдается во множестве книг урало-сибирской традиции [18. С. 12-13].

Проблематика осквернения от иноверцев также широко представлена в сборнике [1. Л. 16, 19 об., 50, 52]. Матерная брань, нравственное нечестие и ложные догматы выступают причиной обособления от их носителя. А.И. Самойленко писал: «Оказавшись во враждебном окружении, старообрядцы, чтобы сохранить неповрежденным древлецерковное благочестие, должны были создать свой мир» [17. С. 356]. Таким образом, бытовая замкнутость старообрядческих общин стала резко осуждаемой церковными миссионерами и рядовым населением, однако весьма эффективной для сохранения их культурной самобытности практикой [19. С. 212]. 
Возникает вопрос относительно того, почему тексты компиляции не разбиты на тематические блоки, а чередуются между собой и многократно повторяют уже обозначенную проблематику. Ответ на данный вопрос дает исследование Н.Д. Зольниковой относительно структуры старообрядческих нравоучительных сборников. По мнению исследовательницы, путем чередования многообразных жанров книжники стремились снизить риск монотонного изложения своего вероучения [2. С. 199, 201-202]. Так, мы можем наблюдать, что, по замыслу составителя, агиографические произведения отделяются друг от друга сочинениями эсхатологического жанра, что усиливает внимание читателей к постоянно стилистически изменяющемуся тексту.

Следующий значительный блок текстов в сборнике представлен четырьмя сочинениями, принадлежащими перу Ефрема Сирина. По всей видимости, включение данных произведений в компиляцию следует объяснять желанием составителя обеспечить сборник высоким уровнем читательского доверия. Ефрем Сирин являлся одним из излюбленных старообрядцами, наряду с Иоанном Златоустом и Максимом Греком, авторов. Учитывая, что авторитет книги и лояльность к ней рядовых читателей напрямую зависел от включенных в нее произведений, мысль об использовании некоторых частей компиляции в большей степени как элемента ее популяризации, нежели важного структурного компонента, выглядит вполне убедительной.

Все четыре сочинения располагаются в непосредственном «соседстве» друг с другом, что однозначно указывает на единство их предназначения в сборнике. Вместе с тем, несмотря на значительный объем каждого из текстов, что обычно определяло доминирующее положение фрагмента в структуре книги, следует заключить, что данный блок не имел решающего значения для устройства компиляции. На это указывает уже то, что фрагменты размещены в завершающей части сборника. Расположение текстов в конце «конвоя» однозначно свидетельствует о второстепенности их содержания для общего идейного повествования.

Так, «Слово об Иосифе Прекрасном» [1. Л. 94123 об.], «Слово о страсти Спасове» [Там же. Л. 140 147] и «Повесть о святом Авраамии» [Там же. Л. 147-173] повторяют общие нравоучительные мотивы о праведности и уповании на Бога, мужественном перенесении искушений и страданий, уже звучавшие в первой части книги. «Слово об антихристе» [Там же. Л. 124-139 об.] также, подобно множеству предыдущих сочинений, пытается ввести читателей в состояние эсхатологического ожидания (для чего традиционно и помещалось в сборники соответствующей тематики [13. С. 176]). Таким образом, несмотря на вполне органичное включение данного блока текстов в состав компиляции, творения Ефрема Сирина, тем не менее не имели решающего значения для ее структуры, так как лишь повторяли уже звучавшие в повествовании мотивы и выполняли лишь второстепенные функции.

Заключительный блок текстов представлен тремя собраниями апостольских, соборных и святоотеческих правил [1. Л. 198-211, 211 об. - 234, 234245 об.]. Большое внимание в выборке правил уделено регламентации семейных и половых отношений. Осуждаются различные формы блуда и, что наиболее для нас интересно, регламентируются правила семейной жизни. Выборка, представленная в сборнике, вполне отчетливо указывает на необходимость отвержения от молитвы разводящихся и даже гнушающихся брака.

В силу этого многократно встречающиеся в произведении призывы бежать из мира и уединиться в пустыне [1. Л. 30-31 об., 41, 56, 61 об.] следует воспринимать не как указание на причастность составителя к согласию странников, а как общее для всех старообрядческих ветвей выступление против мира «победившего антихриста» и тенденцию к самоизоляции. Приверженность браку также исключает возможность принадлежности составителя к крупным сибирским согласиям федосеевцев и филипповцев, первые из которых допускали лишь сохранение уже заключенных браков (строжены), а вторые и вовсе исключали какие-либо супружеские отношения.

Наконец, в числе возможных согласий, распространенных в Западной Сибири, к которым мог бы относиться книжник, явно не было толка часовенных. Так, несмотря на отсутствие у последних священства и исполнения богослужебных обязанностей наставниками, представители согласия не придерживались идеи об истреблении священнического сана перед Страшным судом, которую широко постулирует сборник [1. Л. 17 об., 88]. Совокупность указанных фактов наводит на мысль о том, что наиболее вероятным составителем мог быть представитель согласия поморцев, в значительной степени не утративших своего радикализма даже к концу XIX в.

Подводя итог выполненному исследованию, следует отметить, что несмотря на жанровое разнообразие сборника, все вошедшие в него произведения выступали в качестве конвоя для первых двух сочинений, будучи призваны усиливать их полемический эффект. Яркая полемическая ориентированность книги, воспитывавшая в читателе проповеднический талант, дает основания полагать, что основной аудиторией сборника должны были стать рядовые староверы и наставники общин. При этом книга не предполагала четкой сословной ориентированности в отличие от многих других сборников, читателями которых являлись преимущественно выходцы из крестьянства.

\section{ЛИТЕРАТУРА}

1. Фонд книжных памятников Томского областного краеведческого музея. 7903/26.

2. Зольникова Н.Д. Старообрядческий нравоучительный сборник непостоянного состава // Исторические источники и литературные памятники XVI-XX вв. Новосибирск : Изд-во СО РАН, 2004. С. 178-202.

3. Зольникова Н.Д. «Свои» и «чужие» по нормативным актам сибирских староверов-часовенных // Гуманитарные науки в Сибири. 1998. № 2. С. $54-59$. 
4. Старухин Н.А. Проблема изучения творческого наследия старообрядческого писателя Г.А. Страхова // Гуманитарные науки в Сибири. 2009. № 3. С. 113-115.

5. Источниковедческие и историографические аспекты сибирской истории. Ч. 11 / под общ. ред. Я.Г. Солодкина. Нижневартовск : Изд-во НВГУ, 2016. С. 106-137.

6. Пихоя Р.Г. Записки археографа. М. : Русский фонд содействия образованию и науке, 2016. 496 с.

7. Малышев В.И. Неизвестная повесть XVIII в. о хвастливом книжнике // Русская литература. 1964. № 1. С. 97-99.

8. Бытко С.С. «Старообрядец» в восприятии массовой культуры рубежа XIX-XX вв. (по сочинениям русских писателей «Серебряного века») // Материалы 53-й конференции МНСК-2015: история. Новосибирск : Изд-во НГУ, 2015. С. 77-78.

9. Грицевская И.М. Структура старообрядческих сборников: Соловецкий и Пустозерский циклы в сборнике из Нижегородской областной библиотеки // Вестник Нижегородского университета им. Н.И. Лобачевского. 2009. № 4. С. $288-294$.

10. Отдел редких книжных памятников Научной библиотеки Томского государственного университета. В-27066.

11. Иванова Н.В. Лексические репрезентации оппозиции «свой - чужой» в духовных старообрядческих стихах // Научный диалог. 2014. № 12 (36). С. 24-36.

12. Ключевский В.О. Русская история: полный курс лекций : в 3 т. М. : АСТ, 2002. Т. 2. 592 с.

13. Бытко С.С. Сборник «Слово о лжепророках и лжеучителях»: идея, структура, организация // Тюменский исторический сборник. Тюмень: Изд-во ТюмГУ, 2016. Вып. XVIII. С. 169-180.

14. Протопоп Иван Неронов. Собрание документов эпохи / под ред. К.Я. Кожурина. СПб. : Свое издательство, 2012.372 с.

15. Фишман О.М. «Отче» и колдуны: Образы жизни карельской старообрядческой общины // Обряды и верования народов Карелии: Человек и его жизненный цикл. Петрозаводск : КНЦ РАН, 1994. С. 122-143.

16. Юхименко Е.М., Понырко Н.В. История об отцах и страдальцах соловецких: лицевой список из собрания Ф.Ф. Мазурина. М. : Языки славянской культуры, 2002. 272 с.

17. Самойленко А.И. Лев Феоктистович Пичугин и старообрядцы с. Пойма Пензенской области // Мир старообрядчества. Вып. 4. Живые традиции: результаты и перспективы комплексных исследований русского старообрядчества. М. : РОССПЭН, 1998. С. $356-361$.

18. Бытко С.С. Структурное оформление старообрядческого полемического сборника ХХ века из собрания НБ ТГУ // Югра, Сибирь, Россия: политические, экономические, социокультурные аспекты прошлого и настоящего. Нижневартовск : Изд-во НВГУ, 2015. С. $12-15$.

19. Сморгунова Е.М. Исход староверов вчера и сегодня: уход от мира и поиски земли обетованной // История Церкви: изучение и преподавание : материалы науч. конф., посвящ. 2000-летию христианства. Екатеринбург : Изд-во УрГУ, 1999. С. 211-219.

Статья представлена научной редакцией «История» 3 декабря 2017 г.

\section{POLEMIC CULTURE OF THE OLD BELIEVERS AND THE STRUCTURE OF A MANUSCRIPT COLLECTION OF THE LATE 19TH CENTURY: FEATURES OF INTERACTION}

Vestnik Tomskogo gosudarstvennogo universiteta - Tomsk State University Journal, 2018, 428, $72-77$.

DOI: $10.17223 / 15617793 / 428 / 9$

Sergey S. Bytko, Nizhnevartovsk State University (Nizhnevartovsk, Russian Federation). E-mail: labarum92@rambler.ru

Keywords: Old Believer compilations; Cyrillic tradition; polemical collection; Old Believers; bookishness; manuscript.

The article is devoted to the problem of studying a handwritten Cyrillic collection in the context of the polemical culture of the Old Believers of the late 19th century. An attempt is made to analyze this book, its attribution and to determine the principles of grouping the texts included in it. The book contains 52 works of pre-Reform origin. It should be noted that the first work ("A conversation between a scribe and a boy") sets the general "narrative" tone of the entire collection, which is why, apparently, it was located at the beginning of the collection. As part of the compilation, the composition loses its moralizing motives which confirmed the incomprehensibility of knowledge about God and concentrates the reader's attention solely on the need for a decisive and convincing "stand for the ancient piety". In the second part of the collection, the little-known "Testament of Martyn, a Christian" is presented. The work continues the polemical theme designated in the collection by an introductory fragment. The following forty texts serve as a "convoy" in relation to the first two works. The secondary character of these works in the structure of the collection is indicated by their volume which does not exceed two to three pages. Despite the apparent disorder of the works, they are nevertheless united by the main problems: (1) rules of preaching; (2) eschatological reasoning; (3) hagiography of the martyrs; (4) "contamination" from the gentiles. Works on various subjects constantly alternate inside the "block", with each of the micro-topics repeated many times. According to the concept of the author of the collection, hagiographic works had to be separated from each other by essays of the eschatological genre, which would strengthen the readers' attention to the text constantly changing its style. A conclusion is drawn that in view of the incentive effect that hagiography had on the reader together with dogmatically developed texts, the compiler ultimately counted on the rapid growth of the number of his own community and soglasiye [confession]. The next significant block of texts in the collection is represented by four works belonging to the pen of Ephraim the Syrian. Apparently, the inclusion of these works in the compilation should be explained by the desire of the compiler to provide the collection with a high level of readers' trust. The final block of texts is represented by three collections of apostolic, conciliar and patristic rules. A great deal of attention is given in the sample to the regulation of family and sexual relations. The nature of the texts makes it possible to say that the compiler of the collection was a convinced supporter of marriage. Adherence to marriage excludes the possibility of the compiler's belonging to the large Siberian soglasiyes of Stranniki, Fedoseevtsy and Filippians. The most likely compiler of the collection could be a representative of the Pomorian soglasiye that, to a large extent, did not lose its radicalism even by the end of the 19th century.

\section{REFERENCES}

1. Fund of Book Monuments of the Tomsk Regional Museum of Local Lore. 7903/26.

2. Zol'nikova, N.D. (2004) Staroobryadcheskiy nravouchitel'nyy sbornik nepostoyannogo sostava [Old Believer moralizing collection of nonpermanent composition]. In: Pokrovskiy, N.N. (ed.) Istoricheskie istochniki I literaturnye pamyatniki XVI-XXvv. [Historical sources and literary monuments of the 16th-20th centuries]. Novosibirsk: SB RAS.

3. Zol'nikova, N.D. (1998) "Svoi" i "chuzhie" po normativnym aktam sibirskikh staroverov-chasovennykh ["Friend" and "foe" by the normative acts of the Siberian Chasovennye Old Believers]. Gumanitarnye nauki v Sibiri-Humanitarian sciences in Siberia. 2. pp. 54-59.

4. Starukhin, N.A. (2009) Problema izucheniya tvorcheskogo naslediya staroobryadcheskogo pisatelya G.A. Strakhova [The problem of studying the creative heritage of the Old Believer writer G.A. Strakhov]. Gumanitarnye nauki v Sibiri-Humanitarian sciences in Siberia. 3. pp. 113-115.

5. Solodkina, Ya.G. (ed.) (2016) Istochnikovedcheskie $i$ istoriograficheskie aspekty sibirskoy istorii [Source-study and historiographic aspects of Siberian history]. Pt. 11. Nizhnevartovsk: Nizhnevartovsk State University. 
6. Pikhoya, R.G. (2016) Zapiski arkheografa [Notes of an archeograph]. Moscow: Russkiy fond sodeystviya obrazovaniyu i nauke.

7. Malyshev, V.I. (1964) Neizvestnaya povest' XVIII v. o khvastlivom knizhnike [Unknown story of the 18th century about a boastful scribe]. Russkaya literatura. 1.pp. 97-99.

8. Bytko, S.S. (2015) ["Old Believer" in the perception of mass culture at the turn of the 20th century (according to the writings of Russian writers of the Silver Age)]. Student i nauchno-tekhnicheskiy progress [Student and the scientific-technical progress]. Proceedings of the 53rd conference. Novosibirsk: Novosibirsk State University. pp. 77-78. (In Russian).

9. Gritsevskaya, I.M. (2009) Struktura staroobryadcheskikh sbornikov: Solovetskiy i Pustozerskiy tsikly v sbornike iz Nizhegorodskoy oblastnoy biblioteki [Structure of Old Believers' Collections: Solovetsky and Pustozersky Cycles in a Collection of the Nizhny Novgorod Regional Library]. Vestnik Nizhegorodskogo universiteta im. N.I. Lobachevskogo - Vestnik of Lobachevsky State University of Nizhni Novgorod. 4. pp. 288-294.

10. Rare Books Department of the Tomsk State University Research Library. V-27066.

11. Ivanova, N.V. (2014) Leksicheskie reprezentatsii oppozitsii “svoy - chuzhoy" v dukhovnykh staroobryadcheskikh stikhakh [Lexical representations of the opposition "friend - foe" in the spiritual Old Believer verses]. Nauchnyy dialog. 12 (36). pp. 24-36.

12. Klyuchevskiy, V.O. (2002) Russkaya istoriya: polnyy kurs lektsiy: $v 3 t$. [Russian history: a full course of lectures: in 3 vols]. Vol. 2. Moscow: AST. 13. Bytko, S.S. (2016) Sbornik "Slovo o lzheprorokakh i lzheuchitelyakh": ideya, struktura, organizatsiya [Collection "The Word of False Prophets and False Teachers": idea, structure, organization]. In: Tyumenskiy istoricheskiy sbornik [Tyumen Historical Collection]. Is. XVIII. Tyumen: Tyumen State University. pp. 169-180.

14. Kozhurin, K.Ya. (ed.) (2012) Protopop Ivan Neronov. Sobranie dokumentov epokhi [Protopope Ivan Neronov. Collection of documents of the era]. St. Petersburg: Svoe izdatel'stvo.

15. Fishman, O.M. (1994) "Otche” i kolduny: Obrazy zhizni karel'skoy staroobryadcheskoy obshchiny ["Father" and Sorcerers: Lifestyles of the Karelian Old Believers' Community]. In: Vinokurova, I.Yu. \& Surkhasko, Yu.Yu. (eds) Obryady i verovaniya narodov Karelii: Chelovek i ego zhiznennyy tsikl [Rites and beliefs of the peoples of Karelia: man and his life cycle]. Petrozavodsk: KNTs RAN.

16. Yukhimenko, E.M. \& Ponyrko, N.V. (2002) Istoriya ob ottsakh i stradal'tsakh solovetskikh: litsevoy spisok iz sobraniya F.F. Mazurina [A story of the fathers and sufferers of Solovki: a list from the collection of F.F. Mazurin]. Moscow: Yazyki slavyanskoy kul'tury.

17. Samoylenko, A.I. (1998) Lev Feoktistovich Pichugin i staroobryadtsy s. Poyma Penzenskoy oblasti [Lev Feoktistovich Pichugin and the Old Believers ov v. Poyma of Penza Oblast]. In: Mir staroobryadchestva [World of Old Belief]. Is. 4. Moscow: ROSSPEN. pp. 356-361.

18. Bytko, S.S. (2015) [Structural design of an Old Believer polemic collection of the 20th century from the collection of the TSU Research Library]. Yugra, Sibir', Rossiya: politicheskie, ekonomicheskie, sotsiokul'turnye aspekty proshlogo i nastoyashchego [Ugra, Siberia, Russia: political, economic, sociocultural aspects of the past and present]. Proceedings of the international conference. Nizhnevartovsk: Nizhnevartovsk State University. pp. 12-15. (In Russian).

19. Smorgunova, E.M. (1999) [Exodus of the Old Believers yesterday and today: leaving the society and the search for a promised land]. Istoriya Tserkvi: izuchenie i prepodavanie [History of the Church: study and teaching]. Proceedings of the conference dedicated to the 2000th anniversary of Christianity. Ekaterinburg: Ural State University. pp. 211-219. (In Russian).

Received: 03 December 2017 